\title{
Penerapan Konsep Psikologi Lingkungan Pada Pusat Pendidikan Non Formal Di Kota Surakarta
}

\author{
Tiara Annya ${ }^{1 *}$, Rachmadi Nugroho ${ }^{2}$, Maya Andria Nirawati ${ }^{3}$ \\ Program Studi Arsitektur, Fakultas Teknik, Universitas Sebelas Maret ${ }^{1}$ \\ Email: tiara.annya14@gmail.com* \\ Program Studi Arsitektur, Fakultas Teknik, Universitas Sebelas Maret ${ }^{2}$ \\ Program Studi Arsitektur, Fakultas Teknik, Universitas Sebelas Maret ${ }^{3}$
}

\begin{abstract}
One of the cities in Indonesia that has problems with school dropout children due to economic problems is Surakarta City. By 2015, 1.54\% of workers in this city are teenagers and as many as 6.08\% of the population are unemployed (Ermawati, 2015). In fact, the world has become more open and the competition both in the field of economy and employment becomes increasingly tight. One solution to solve the problem is with non formal education. Non-formal education serves as a substitute or additional education that can increase both academic and life skills. Another problem that arises is how to improve motivation and stimuli in processing learning for those who drop out of school. This can be achieved by applying the concept of environmental psychology to the design of educational facilities. By using the concept of environmental psychology, the learning activities can run effectively and learners become more creative and innovative. Non formal education system provided at this education center are life skills training, pursuing equalization packages and tutoring. Each of these activities has its own support rooms such as theory classrooms, practice spaces, library, studio and auditorium which each room apply the concept of environmental psychology in its design.
\end{abstract}

Keywords: education, non formal education, Surakarta City, environmental psychology

\section{PENDAHULUAN}

Putus sekolah menjadi salah satu masalah yang sangat lazim di Indonesia. Biasanya hal ini terjadi pada anak-anak usia remaja (sekitar umur 12 tahun) yang memiliki keterbatasan ekonomi. Kebanyakan dari mereka putus sekolah karena tidak memiliki biaya untuk membayar sekolah dan lebih memilih untuk menghabiskan waktunya membantu bekerja dibandingkan bersekolah. Sebagai upaya menekan angka putus sekolah ini, sebenarnya pemerintah telah berupaya dengan mengadakan sekolah gratis dan program Wajar (wajib belajar) 9 atau 12 tahun. Namun dikarenakan waktu pendidikannya yang lama dan cenderung hanya berorientasi akademik, masih banyak anak yang lebih memilih tidak melanjutkan pendidikannya.

Dalam Undang Undang No. 20 Tahun 2003 tentang Sistem Pendidikan Nasional, sistem pendidikan di Indonesia dibagi atas sistem pendidikan sekolah (formal) dan sistem pendidikan luar sekolah (non formal). Pendidikan formal dianggap lebih berorientasi akademik, memiliki waktu belajar yang panjang dan biaya pendidikan yang cukup tinggi (Sudjana D., 2000). Sedangkan sistem pendidikan non formal dapat berfungsi sebagai pendidikan pengganti maupun pendidikan tambahan yang memiliki bentuk dan isi yang lebih variatif disesuaikan dengan kebutuhan 
peserta didik dengan jam belajar yang fleksibel.

Pentingnya pendidikan semakin terasa ketika dunia semakin berkembang dan persaingan kualitas tidak dapat dihindari. Kualitas tenaga kerja misalnya. Tenaga kerja dengan tingkat pendidikan yang tinggi atau yang bersertifikat kerja akan diberi upah yang lebih tinggi dibandingkan tenaga kerja yang tingkat pendidikannya rendah atau bahkan tidak mengenyam pendidikan sama sekali. Begitu pula persaingan ekonomi yang semakin menuntut kreatifitas dan inovasi agar bisa bersaing dengan baik di dunia luas. Jika tidak dapat bersaing, maka tak jarang individu akan menjadi pengangguran.

Kota Surakarta merupakan kota di Jawa Tengah yang memiliki angka serapan kerja tinggi, yakni sekitar 93.78\%. Dari angka tersebut, sebanyak $1.45 \%$ merupakan angkatan kerja berusia muda (15-19 tahun). Dikutip dari solopos.com (8/4/2015), sebanyak 17.496 orang Solo adalah pengangguran $(6.08 \%)$ (Ermawati, 2015). Berdasarkan data tersebut maka untuk ikut berpartisipasi dalam persaingan dunia, Kota Surakarta harus dapat meningkatkan kualitas pendidikan dan tenaga kerjanya. Kota ini membutuhkan suatu pusat pendidikan yang tidak hanya berfokus pada akademis, tetapi juga pada usaha belajar dan meningkatkan kecakapan kerja. Salah satu hal yang dapat dilakukan untuk mencapai tujuan tersebut adalah dengan mengadakan sebuah fasilitas pendidikan non-formal.

Sebagai suatu sarana pendidikan, lingkungan pendidikan harus dirancang dengan baik sehingga dapat mengakomodasi kebutuhan penggunanya sekaligus memberikan suasana yang dapat mendukung proses pembelajaran dan pelatihan. Kondisi lingkungan sangat berpengaruh terhadap perilaku manusia, maka diperlukan suatu usaha untuk mewujudkan lingkungan pendidikan yang mendukung proses dan tingkah laku tersebut. Lingkungan tersebut dapat dicapai dengan menerapkan konsep psikologi lingkungan. Psikologi lingkungan adalah ilmu yang mempelajari kaitan antara tingkah laku manusia dan lingkungannya; berusaha mempelajari bagaimana motivasi, sikap, perasaan dan sebagainya dari manusia terhadap lingkungannya dan diharapkan dapat meramalkan bahkan merekayasa perilaku manusia demi pembangunan yang berwawasan lingkungan (Sarwono,1992:3).

\section{METODE}

Metode yang digunakan dalam merancang Pusat Pendidikan Non Formal di Kota Surakarta ini adalah dengan mengolah desain berdasarkan kriteria perancangan lingkungan sesuai dengan konsep psikologi lingkungan yang disesuaikan dengan hasil penelitian mengenai efek psikologis desain fasilitas pendidikan terhadap peserta didik.

Dalam buku yang berjudul "Psikologi Lingkungan" yang ditulis oleh Sarlito Wirawan Sarwono pada tahun 1992, kriteria perancangan lingkungan tersebut adalah:

- Kemudahan Tingkah Laku

Kriteria ini dibagia atas: (1) Fungsional yang berarti desain harus memiliki fungsi sesuai dengan lingkungannya; dan (2) Keleluasaan yang memiliki arti bahwa setiap desain harus disesuaikan dengan daya tamping dan kegiatan yang diwadahi.

- Menjaga Kondisi Fisiologis

Kriteria ini terdiri atas: (1) suhu dan kelembaban udara yang harus disesuaikan dengan ambang toleransi pengguna lingkungan; dan (2) sarana pencegah keadaan darurat untuk mengantisipasi terjadinya keadaan yang mendesak seperti kebakaran, gempa dan sebagainya.

- Menjaga Kondisi Indera

Kriteria ini terdiri atas: (1) Merangsang indera yang berarti desain harus bisa merangsang indera seperti misalnya terdapat cukup cahaya untuk melihat; dan 
(2) keseimbangan indera yang berarti desain harus memiliki cukup rangsang, tidak terlalu banyak dan tidak terlalu sedikit.

- Menjaga Kondisi Sosial

Kriteria ini terdiri dari: (1) rangsangan sosial seperti misalnya tersedia ruang untuk berinteraksi dan berkumpul, area rekreasi, kantin atau taman; dan (2) Isolasi sosial yaitu area dimana seorang individu bisa menyendiri dan menjaga privasinya seperti toilet atau bilik belajar mandiri.

Kriteria perancangan lingkungan tersebut kemudian diperinci dengan menerapkan hasil penelitian yang berkaitan dengan efek psikologis desain fasilitas pendidikan terhadap peserta didik. Rincian yang digunakan ini terdapat dalam sebuah rangkuman tinjauan pustaka yang dirangkum oleh University of Newcastle dengan judul "The Impact of School Environments: A literature review"

Pusat Pendidikan Non Formal yang dirancang penulis akan menerapkan keempat kriteria tersebut beserta turunannya dalam pengolahan tapak, pengolahan massa dan tampilan bangunan serta pengolahan ruang sehingga didapatkan hasil akhir desain yang sesuai dengan psikologi lingkungan.

\section{HASIL DAN PEMBAHASAN}

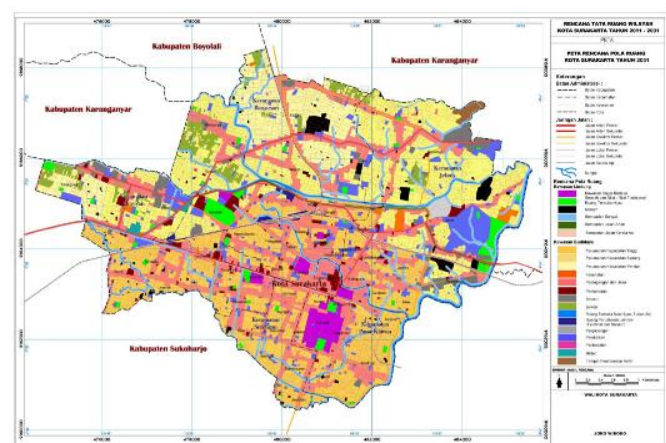

Gambar 1: Rencana Tata Ruang Wilayah Kota Surakarta Tahun 2011-2031

(Sumber: PERDA Kota Surakarta Nomor 1

Tahun 2012 tentang Rencana Tata Ruang

Wilayah Kota Surakarta Tahun 2011-2031)
Pusat pendidikan Non Formal ini akan berlokasi di Kelurahan Mojosongo, tepatnya di Jalan Jaya Wijaya, Kelurahan Mojosongo, Kecamatan Jebres, Kota Surakarta. Dalam Rencana Tata Ruang Kota Surakarta Tahun 2011-2031, kelurahan Mojosongo memiliki fungsi lahan yang dapat dimanfaatkan dalam sektor apapun, termasuk sektor pendidikan (lihat Gambar 1).

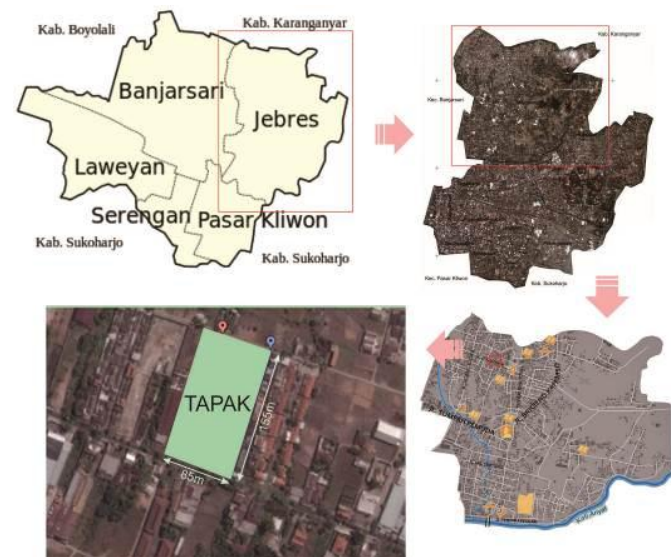

Gambar 2: Lokasi Tapak

Tapak yang terpilih adalah tapak yang berada di Jalan Jaya Wijaya, dengan ukuran lahan 85 meter x 155 meter dan luasan lahan sekitar $13.172 \mathrm{~m}^{2}$ (lihat Gambar 2). Tapak ini memenuhi kriteria yang sesuai dengan kriteria pemilihan tapak untuk bangunan pendidikan, yakni dekat dengan jalan utama yang tidak terlalu bising dan tidak terlalu padat, dekat dengan pemukiman warga sehingga mudah dicapai, dekat dengan rumah sakit untuk kemudahan jika terjadi keadaan darurat, dekat dengan pusat peribadatan dan pusat perdagangan, serta memiliki kontur lahan yang datar. Orientasi tapak mengarah ke barat daya (arah jalan utama) dengan intensitas pencahayaan matahari yang baik mengingat Kota Surakarta berada di daerah tropis dengan intensitas pencahayaan matahari dan curah hujan yang cukup tinggi setiap musimnya. Keadaan sekeliling tapak dapat dilihat pada Gambar 3. 


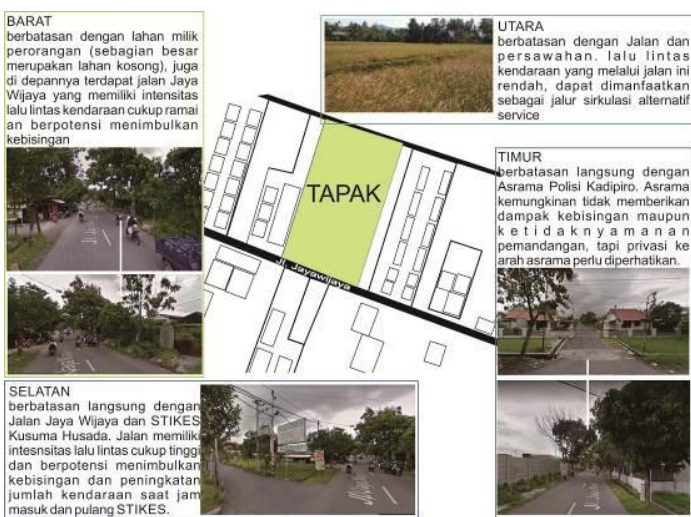

Gambar 3: Lingkungan di sekitar tapak

Penerapan kriteria perancangan akan dikelompokkan atas penerapan kriteria pada pengolahan tapak, penerapan kriteria pada pengolahan massa dan tampilan bangunan, serta penerapan kriteria pada pengolahan ruang. Penerapan kriteria tersebut adalah sebagai berikut:

\section{A. Pengolahan Tapak}

Zona tapak dibagi atas dua zona utama, yaitu zona pengelola dan zona pendidikan (lihat Gambar 4). Zona pengelola ditempatkan berada di dekat entrance tapak dengan pertimbangan area pengelola sebagai simbol penerima dan yang menjalankan kegiatan pendidikan, sedangkan zona pendidikan berada di bagian dalam tapak dengan pertimbangan privasi, menjaga keseimbangan rangsang terutama akibat kebisingan dari jalan utama, memudahkan kegiatan sesuai dengan fungsinya sehingga tidak terganggu aktivitas ke luar tapak, serta memudahkan interaksi khususnya peserta didik tanpa terganggu kegiatan pengelolaan.

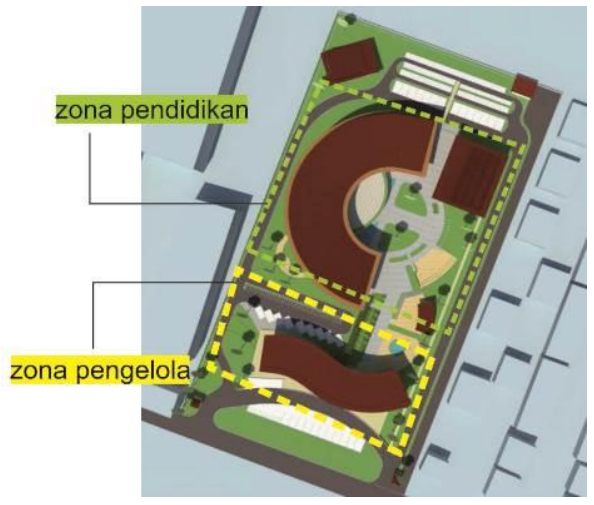

Gambar 4: Zona Utama pada Tapak
Pola sirkulasi pada tapak digunakan menggunakan sistem sirkulasi satu arah (garis kuning dan merah muda pada gambar) untuk menghindari adanya crosscirculation dengan adanya jalan utama yang dapat dilalui kendaraan dan ketersediaan pedestrian (lihat Gambar 5). Pemilihan sistem sirkulasi ini juga dimaksudkan untuk memudahkan evakuasi jika terjadi hal-hal darurat, serta menghindari adanya disorientasi. Area parkir juga dibagi berdasarkan penggunanya, yaitu area parkir pengunjung, area parkir pengelola, dan area parkir peserta didik yang masingmasing ditempatkan berdekatan dengan bangunannya (lihat Gambar 5).

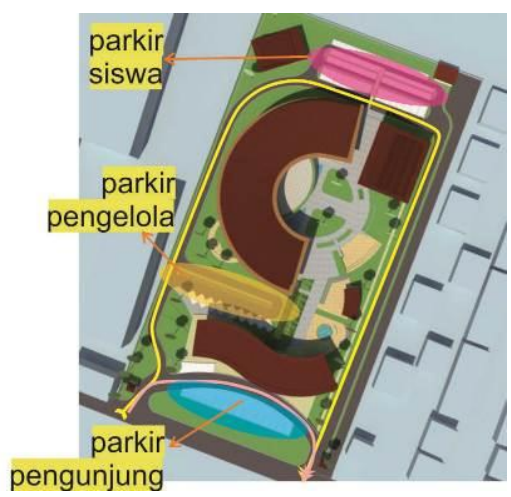

Gambar 5: Pola Sirkulasi dan Pembagian Area Parkir pada Tapak

Tidak hanya mengolah penempatan massa bangunan, tapak juga diolah sehingga memiliki ruang terbuka hijau (lihat Gambar 6) sebagai sarana relaksasi, perangsang indera, sekaligus sebagai filter udara yang secara psikologis keberadaan ruang terbuka hijau ini dapat meningkatkan inspirasi dan kreatifitas bagi pengamatnya, serta memberikan rasa bebas dan rileks. Selain itu, pada area tapak juga disediakan ruang kelas outdoor (lihat Gambar 6). Ruang ini memiliki fungsi sebagai area belajar luar ruangan yang dapat meningkatkan rangsang indera dalam menerima materi pembelajaran, meningkatkan inspirasi dan kreatifitas karena secara psikologis otak tidak merasa "dibatasi". Pencahayaan alami langsung dari matahari juga berdasarkan hasil penelitian terbukti dapat memperlancar proses kognisi. 


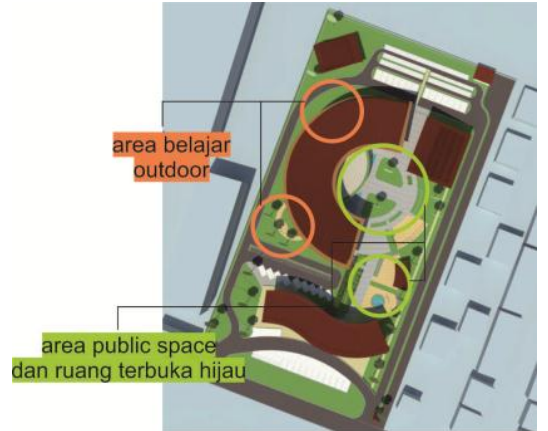

Gambar 6: Pengolahan Massa dan Ruang Terbuka Hijau pada Tapak

\section{B. Pengolahan Massa dan Tampilan Bangunan}
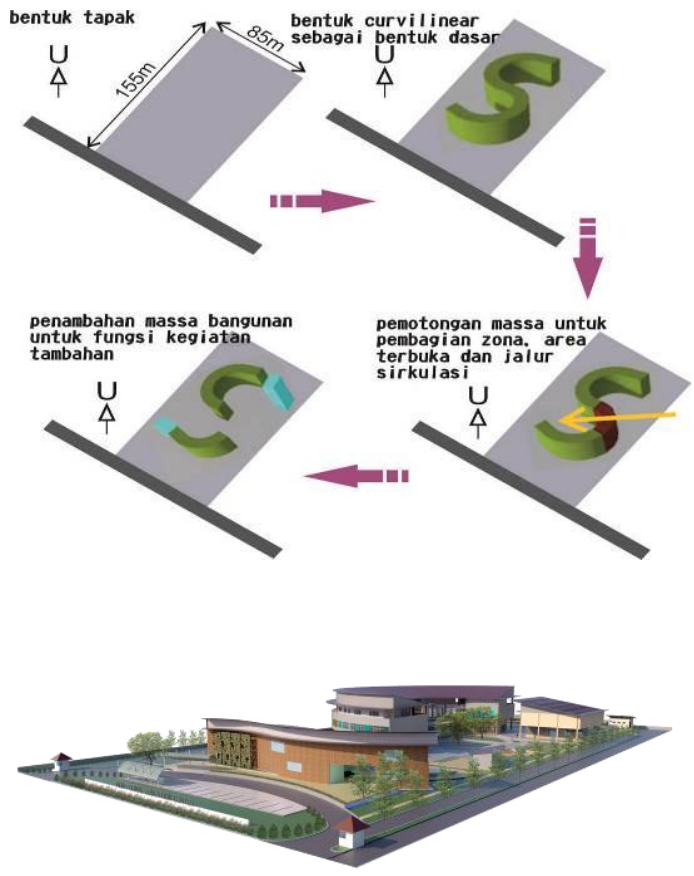

Gambar 7: Gubahan Massa Bangunan

Massa pada tapak mengambil bentuk massa berupa curvilinear, yaitu bentuk yang melengkung dan tidak memiliki sudut yang tajam. Secara psikologis, bentuk ini dianggap merupakan bentuk yang "aman" bagi otak karena tidak diinterpretasikan sebagai bahaya (biasanya otak merasa dalam bahaya jika melihat sudut-sudut yang tajam) (Bradshaw, 2015). Selain itu, bentuk ini juga bisa mewakili konsep "non formal" yang diusung oleh pusat pendidikan ini. Bentuk dasar tersebut kemudian melalu proses gubahan sehingga akhirnya didapatkan bentuk akhir yang sesuai (lihat Gambar 7).

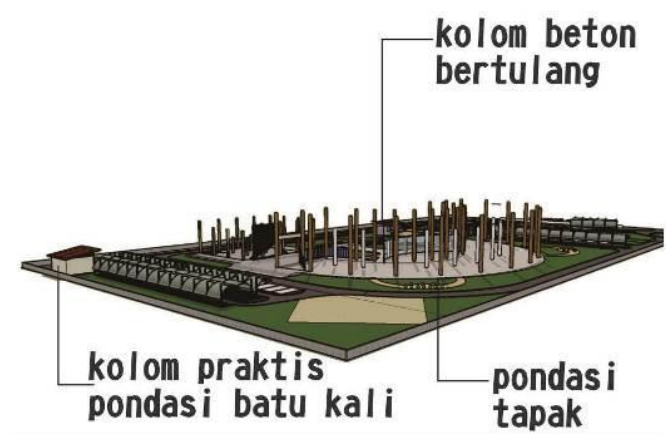

Gambar 8: Sistem Struktur Bnagunan

Untuk mengakomodasi kekuatan bangunan dan kebutuhan ruang di dalamnya, maka dipilihlah sistem struktur rigid frame. Sistem struktur ini memungkinkan luasan ruang yang fleksibel tanpa megganggu kekuatan bangunan. Rigid frame yang digunakan ini memiliki sistem grid melengkung pada bangunan utama dengan modul $8 \mathrm{~m}$ x $8 \mathrm{~m}$, sedangkan pada bangunan pendukung seperti perpustakaan menggunakan sistem grid dengan modul $5 \mathrm{~m} \times 5 \mathrm{~m}$. pondasi yang digunakan adalah sistem pondasi tapak (footplate) untuk bangunan dengan ketinggian 2 lantai dan 3 lantai, sedangkan untuk bangunan satu lantai seperti bangunan mushola, ruang servis dan kafetaria menggunakan sistem pondasi batu kali menerus (lihat Gambar $8)$.

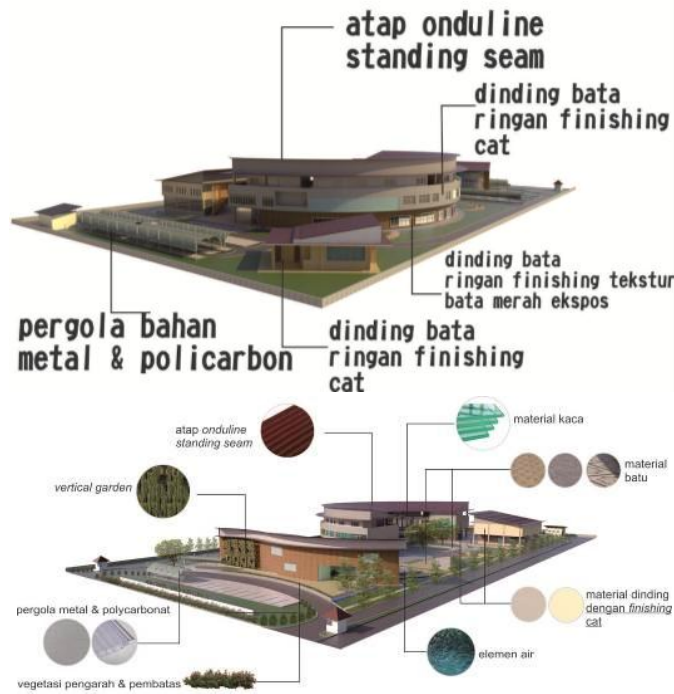

Gambar 9: Material yang digunakan pada Bangunan

Tampilan bangunan mengusung penggunaan material dengan warna, tekstur dan bahan yang beragam. Hal ini untuk 
menimbulkan rangsang yang beragam pada pengamatnya. Seperti misalnya penggunaan pasangan batu bata ekspos pada dinding yang memberikan efek alamiah dan membangkitkan semangat; penggunaan material kaca pada dinding untuk memberikan kesan yang luas, menyatu dan terbuka; penggunaan dinding dengan finishing cat berwarna lembut untuk memberikan efek yang tenang, teduh dan lembut; material batu, air dan kayu untuk memberikan efek yang alamiah, indah dan hangat. Selain itu juga terdapat pepohonan yang berfungsi sebagai peneduh, pengarah dan penyaring udara; semak-semak sebagai pembatas dan pengarah; serta rerumputan sebagai salah satu elemen penutup tanah selain paving block (lihat Gambar 9).

\section{Pengolahan Ruang}

Sistem ruang pada desain Pusat Pendidikan Non Formal ini terdiri atas sistem ruang luar dan sistem ruang dalam. Ruang luar terdiri atas area drop off penumpang, ruang kelas outdoor, taman serta amphitheater. Sedangkan ruang dalam merupakan ruang yang berada di dalam bangunan, seperti ruang kelas, ruang pengelola, ruang pengajar, dan sebagainya.

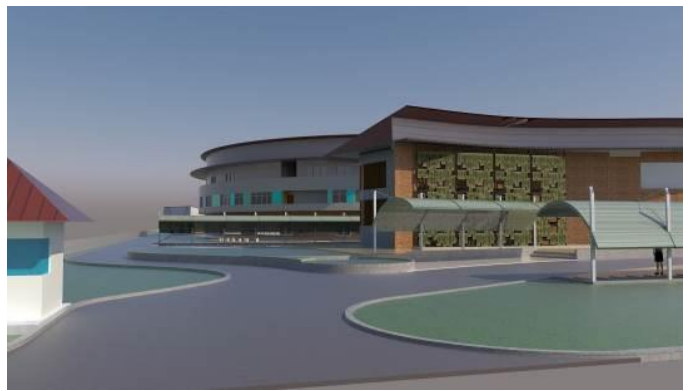

Gambar 10: Area Drop Off Pengunjung

Area drop off penumpang (lihat Gambar 10) ditempatkan di dekat entrance utama tapak, dengan keberadaan pergola dan pohon besar sebagai penanda, serta paving yang berbeda warna dengan jalan sebagai pembatas area. Ruang belajar outdoor (lihat Gambar 11) disediakan sebagai alternatif ruang belajar agar kegiatan pembelajaran tidak terasa monoton dan membosankan, selain itu siswa juga dapat menghirup udara segar dan mengamati pemandangan di sekelilingnya sehingga tercipta perasaan bebas, rileks, terbuka dan kreatif.

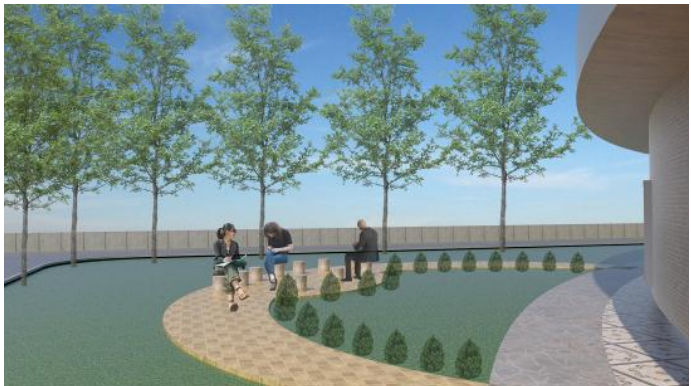

Gambar 11: Ruang Kelas Outdoor

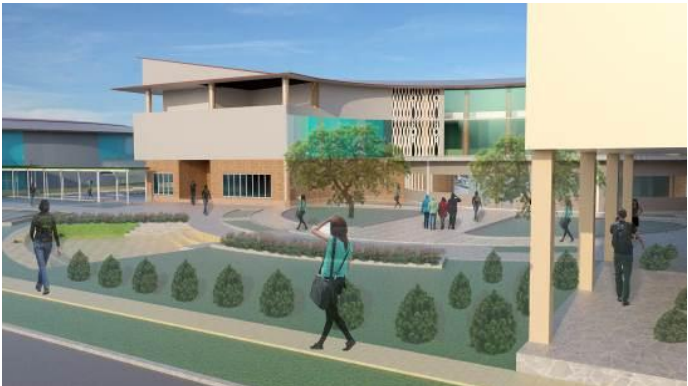

Gambar 12: Taman dan Amphitheatre

Taman dan amphitheatre (lihat Gambar 12) memiliki fungsi sebagai sarana berinteraksi maupun menyendiri serta sebagai sarana relaksasi. Penggunaan material yang beragam dengan mengutamakan material yang berasal dari alam seperti batu-batuan, pohon dan unsur air dapat menimbulkan efek psikologis yang menenangkan, bebas dan sejuk. Area outdoor ini menjaga intensitas cahaya dan suhu udara dengan menerapkan banyaknya pepohonan, serta adanya kolam yang dapat berfungsi sebagai peneduh dan penyejuk sehingga pengguna dapat tetap nyaman meskipun berada di luar ruangan.

Bagian ruang dalam, terutama ruang kelas sebagai ruang utama kegiatan pembelajaran menerapkan berbagai macam penerapan konsep psikologi lingkungan, seperti kemudahan akses dengan sistem penempatan ruang linear, luasan ruang yang fleksibel, tidak membentuk sudut tajam, furniture yang bisa dipindah-pindah dengan mudah, bentuk ergonomis, penggunaan warna dan material yang dapat merangsang dan menjaga keseimbangan 
rangsang, serta pencahayaan alami dan buatan yang dapat membantu proses pembelajaran (lihat Gambar 13).

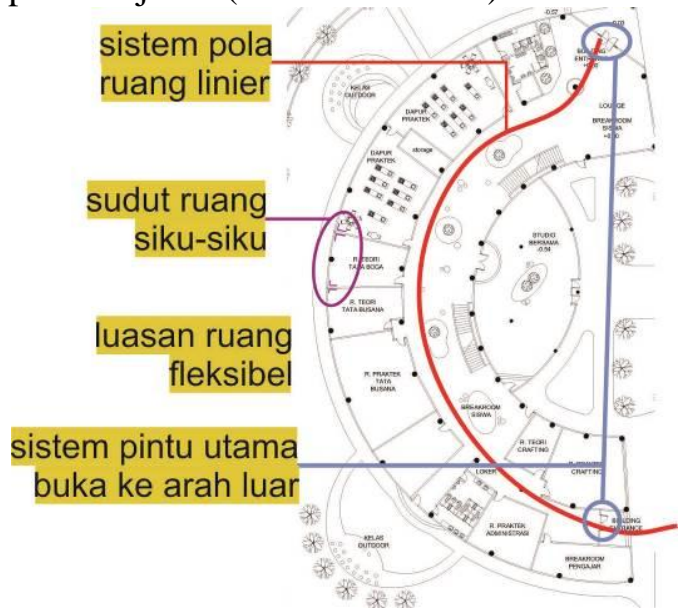

Gambar 13: Sistem Peruangan Ruang Dalam

Luasan ruang yang fleksibel memudahkan perubahan dalam konfigurasi ruang sehingga tidak menimbulkan rasa monoton dan bosan. Serta dapat mengakomodasi kegiatan di dalamnya. Penggunaan furnitur yang mudah dipindahkan dan bentuk yang ergonomis memiliki tujuan psikologis agar bentuk dalam ruang dapat ditata dengan mudah, dapat mengakomodasi keinginan peserta didik dalam melakukan pembelajaran, misalnya ingin belajar mandiri maupun berkelompok, serta bentuk ergonomis tersebut dapat merangsang otak untuk berpikiran lebih terbuka dan lebih nyaman untuk digunakan (lihat Gambar 14).

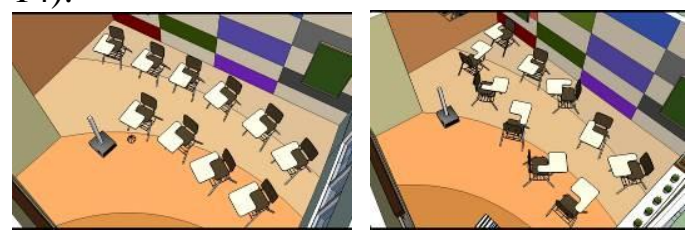

Gambar 14: Luasan Ruang Fleksibel yang

Memudahkan Perubahan dan penambahan Furnitur

Pemilihan warna dan material yang beragam memiliki fungsi untuk merangsang kreatifitas (dekorasi warna yang cerah di dinding bagian belakang kelas), memberikan suasana yang tidak monoton dengan tekstur dan warna lembut (dinding di bagian bukaan dan lantai yang bergradasi warna), serta penggunaan dinidng polos dengan finishing cat warna yang lembut tanpa dekorasi di bagian belakang papan tulis yang berfungsi agar pada saat pengajar memberikan materi, konsentrasi peserta didik tidak teralihkan pada dekorasi di bagian dinding dan warna yang lembut tersebut juga membuat mata tidak mudah lelah (lihat Gambar 15).

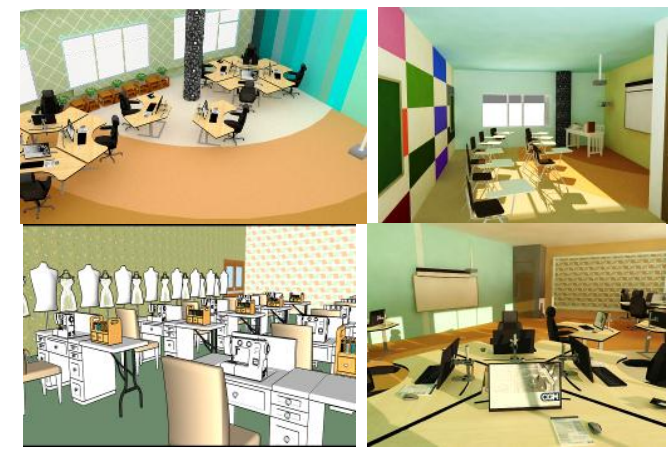

Gambar 15: Keberagaman Warna dan Material Tiap Ruang

\section{KESIMPULAN}

Kota Surakarta memiliki potensi yang besar untuk mengembangkan sistem pendidikan non formal untuk mengurangi angka putus sekolah dan meningkatkan kualitas pendidikan maupun tenaga kerja. Sebagai upaya untuk meningkatkan minat belajar, diperlukan sistem belajar yang sesuai dan desain fasilitas pendidikan yang dapat mendukung sistem pembelajaran tersebut sekaligus dapat merangsang proses kognisi penggunanya. Psikologi lingkungan dapat menjadi solusi dalam mengatasi permasalahan tersebut.

Psikologi lingkungan dalam konsep desain Pusat Pendidikan Non Formal ini dapat menjadi salah satu usaha yang dapat meningkatkan motivasi dan rangsangan belajar pada fasilitas pendidikan. Desain yang tidak monoton dan dengan sistem pembelajaran yang tidak formal dapat menarik perhatian remaja maupun dewasa untuk kembali belajar sehingga dapat menambah maupun mengembangkan ilmunya. Penerapan kriteria perancangan lingkungan dengan prisnsip psikologi lingkungan pada Pusat Pendidikan Non Formal ini diterapkan pada: 


\section{A. Pengolahan Tapak}

Kriteria perancangan lingkungan yang diterapkan pada tapak adalah kriteria kemudahan tingkah laku yang diterapkan pada pembagian zona; kriteria menjaga kondisi fisiologis, kriteria menjaga kondisi indera dan menjaga rangsang sosial pada penataan lansekap; serta kriteria menjaga tingkah laku dan sarana pencegah keadaan darurat pada sistem sirkulasi tapak.

\section{B. Pengolahan Massa dan Tampilan Bangunan}

Penerapan kriteria perancangan berdasarkan psikologi lingkungan pada gubahan massa dan sistem struktur memperhatikan kriteria kemudahan tingkah laku dan rangsang indera yang diwujudkan pada bentuk dasar massa bangunan dan sistem struktur yang digunakan; sedangkan tampilan bangunan dan material yang digunakan memperhatikan kriteria keseimbangan indera dan suhu udara.

\section{Pengolahan Ruang}

Pengolahan ruang baik ruang dalam maupun ruang luar menerapkan semua kriteria perancangan berdasarkan psikologi lingkungan, mulai dari menjaga kemudahan tingkah laku yang diterapkan pada besaran ruang dan perbedaan tiap-tiap ruang sesuai fungsinya; penerapan kriteria menjaga kondisi fisik yang diterapkan pada bukaan, elemen peneduh dan sistem sirkulasi dalam bangunan; penerapan kriteria menjaga kondisi indera yang diterapkan pada variasi warna dinding, dekorasi dan bentuk furnitur yang ergonomis; serta menjaga kondisi sosial yang diwujudkan dengan adanya ruang berinteraksi maupun runag yang bersifat privat.

\section{REFERENSI}

Bradshaw, J. (2015, June 1). The Psychology of Space, Part 1. Retrieved from http://magazine.iavm.org/article/thepsychology-of-space-part-1/

Ermawati, R. (2015, April). PENGANGGURAN SOLO : 17.496
Warga Kota Bengawan Menganggur, Ini Sebabnya. Retrieved October 21, 2016, from http://www.solopos.com/2015/04/08/ pengangguran-solo-17-496-wargakotabengawan-menganggur-inisebabnya-592582

PERDA Kota Surakarta Nomor 1 Tahun 2012 tentang Rencana Tata Ruang Wilayah Kota Surakarta Tahun 2011-2031

Sarwono, S. W. (1995). Psikologi Lingkungan. Jakarta: Grasindo.

Sudjana, D. (2000) Pendidikan Luar Sekolah, Bandung: Falah Production.Sudjana,D.

Teaching, T. C. (2005). The Impact of School Environments: A literature review.

Undang Undang Republik Indonesia Nomor 20 Tahun 2003 tentang Pendidikan 